\title{
PULMONARY EMBOLISM AND THROMBOSIS
}

\author{
R. Marshall, M.D., M.R.C.P. \\ Nuffield Department of Surgery, Radcliffe Infirmary, Oxford
}

SuDDEN death following a call for a bedpan is a classical mode of presentation of pulmonary embolism, but it is probable that cases of this severity form only a small proportion of the total. Pulmonary embolism may be caused by blood clot, fat, cells or foreign bodies, but most commonly by blood clot.

\section{The Physiological Effects}

The physiological effects of pulmonary embolism depend upon the size and number of the emboli and they may produce these effects either by mechanical blockage of the circulation when they are of sufficient size or number, or by the initiation of reflex broncho- or vasoconstriction. This point is of considerable clinical importance because of the possibility that reflex effects may be reduced by drug treatment, whereas mechanical blockage is less likely to be affected by drugs. There has been much controversy over the part played by reflex action in causing the symptoms and disability of pulmonary embolism. Removal of one lung in man has no effect on the pulmonary arterial pressure and causes very little respiratory disability. Dogs are able to live with less than $25 \%$ of their pulmonary vascular bed remaining. These observations have led people to suppose that in clinically severe pulmonary embolism the thrombus itself is unlikely to block so much of the pulmonary vascular tree that it can cause right heart failure. It has been supposed that reflexes, initiated by impaction of emboli in the smaller arteries, cause reflex vasoconstriction of the whole of the pulmonary vessels. Much experimental work has been done to try to determine the role played by reflex action in pulmonary embolism. Reflex vasoconstriction has been demonstrated in the contralateral lung of dogs when small glass beads are injected into the other lung, care being taken that none of the beads escaped from the embolized lung (Niden and Aviado, 1956). Most of the investigators attribute reflex activity to emboli which lodge in vessels of $100 \mu$ or less in diameter, i.e. in the arterioles. In man a balloon inflated in the main pulmonary artery produces no reflex effects, but an instance has been reported of chest pain and ECG changes when the balloon was inflated in a smaller artery (Brofman, Charms, Kohn, Elder, Newman and Rizika, 1957). On the other hand, it is a common practice to impact the tip of a cardiac catheter in branches of the pulmonary artery of about $2 \mathrm{~mm}$. diameter with no ill effects. In spite of the undoubted ability of emboli to produce reflex effects under certain circumstances, there is a growing body of evidence that the effects of pulmonary embolism by inert particles are produced by the magnitude of the mechanical blockage of the pulmonary vessels and are not dependent upon the size of the emboli or reflex vasoconstriction (Daley, I957; McEvoy, Harder and Dale, 1958; Williams, 1956). Comroe, van Lingen, Stroud and Roncoroni (1953) have suggested that some of the effects of pulmonary embolization may be caused by serotonin liberated from the platelets in a thrombus. Serotonin is one of the few substances with a strong vasoconstrictor action on the pulmonary arteries. Following pulmonary embolization of dogs with autologous blood-clot the level of serotonin in the arterial blood has not been found to be raised (Sanders, Waalkes, Gilbert and Terry, 1959), but this is probably an insensitive way of detecting the liberation of serotonin in the lungs. Work in progress suggests that the cardiovascular effect of embolization by platelet agglutinates is greater than that of an equivalent mass of blood clot and this difference may be due to the serotonin liberated.

With this physiological evidence in mind it is useful to consider the clinical picture. Small emboli, if they do not produce reflex vasoconstriction, will cause no symptoms and give rise to no signs; they will therefore pass unnoticed. A single large embolus will have to obstruct more than one main pulmonary artery if it is to cause symptoms in a subject with normal lings. This raises the problem of the importance and the incidence of repeated small pulmonary emboli which could in time obstruct so much of the pulmonary vascular tree that heart failure $r$ ssulted, or could quietly reduce the size of the pulmonary vascular bed so that when a massive pulmonary embolism did occur it could be fatal. 


\section{Detection of Emboli}

Because of the clinical importance of silent, repeated pulmonary embolism it would be of value to know when and under what circumstances silent pulmonary embolism occurs and to what extent the body's defence mechanisms are able to deal with the emboli. Pulmonary emboli may not be detectable clinically or by X-ray or ECG examination and other methods of investigation may have to be used. A method which promised to be of some use was the measurement of the difference in carbon dioxide tension $\left(\mathrm{PCO}_{2}\right)$ between the end tidal gas and the arterial blood. In a subject with uniform distribution of gas in his lungs the air sampled at the end of a normal breath is representative of the gas from the alveoli and this should have the same $\mathrm{PCO}_{2}$ as the arterial blood, since the alveolar wall presents no diffusion barrier to carbon dioxide. If some of the alveoli have no blood supply, because the arteries have been blocked by emboli, then these alveoli will contain no carbon dioxide and the gas from these alveoli will dilute the carbon dioxide in the gas coming from alveoli perfused with blood and so the end tidal (alveolar) $\mathrm{PCO}_{2}$ will be less than that measured simultaneously in the artery. This method, suggested by Severinghaus (Severinghaus and Stupfel, 1957), could, in theory, give a measure of the proportion of alveoli from which the blood supply has been cut off. Experimenta work on dogs (Julian, Travis, Robin and Crump, 1960) and observations in man (Robin, Forkner, Bromberg, Croteau and Travis, I960) have suggested that the method may indicate the extent of pulmonary artery obstruction following embolism. More recently Severinghaus, Swenson, Finley, Lategola and Williams (I96I) have found that the difference between end tidal and arterial $\mathrm{PCO}_{2}$ is much less than would be expected from the amount of pulmonary circulation obstructed. The reason for this is a compensatory mechanism by which abolition of the blood supply to a part of the lung causes a reflex bronchoconstriction which reduces the ventilation to that part. Measurements of the end tidal, arterial $\mathrm{PCO}_{2}$ difference before and after experimental pulmonary embolism of dogs with blood thrombi (Marshall, Allison, Bosman, Sabiston and Dunnill, in preparation) have also shown only small and variable values for the $\mathrm{PCO}_{2}$ difference, but in these dogs the ventilation in the embolized lung was reduced by only a small amount. The end-tidal, arterial $\mathrm{PCO}_{2}$ difference will be considerably reduced if, instead of the embolus completely blocking a lung or a region of a lung, it only partly obstructs it and still allows some blood to flow to the region. Oxygen uptake measurements in dogs with large pulmonary emboli suggest that some blood does get past a large embolus and the blood flow to an embolized region may start to increase only a few minutes after the embolus impacts.

Measurement of the diffusing capacity of the lungs may provide another method for the detec $\overrightarrow{\vec{v}}$ tion of pulmonary embolism. The diffusingo capacity of the lungs is most conveniently measuredo as the diffusing capacity for carbon monoxide and $\overline{\bar{c}}$. it is a measure both of the permeability of thep alveolar membrane to carbon monoxide and of the surface area of the alveolar membrane in contact ${ }^{\text {s }}$ with blood in the capillaries. If the blood supply. to some of the alveoli is cut off the diffusing $\overrightarrow{-}$ capacity will be reduced and the reduction in dif ${ }^{-\infty}$ fusing capacity, in the absence of other lung disease, may give an indication of silent pulmonary 3 embolism. The single breath method of measure-i ment of the diffusing capacity for carbon monoxide $\infty$ is probably particularly useful for this purpose because the full inspiration which is necessary forthis test probably minimizes any inequality of ventilation which might be caused by the emboliza-tion. The usefulness of the method would depend on the detection of a fall in diffusing capacity onf repeated measurements; the normal range is toon wide for a single measurement to be of value.

\section{Clinical Features}

Small or medium-sized pulmonary emboli mấ be completely 'silent'. Larger emboli, whicho cause gross obstruction of the pulmonary circulation, cause the sudden onset of symptoms. Dyspnœa is often the main symptom and may be the only one. A history of sudden attacks of dyspnœa is often obtained from patients who have hado recurrent emboli. The cause of the dyspnœa, as of the dyspnœa secondary to pulmonary hypertension, is not known. It may be reflex from distension of the right side of the heart or it may을 result from inadequate blood supply to the respiratory muscles. Pain in the chest may be of two 3 types. First, massive embolism may cause substernal pain or discomfort similar to that of myocardial infarction. This may arise from distension of the pulmonary artery or may be of myocardial origin due to reduction in coronary blood flow. $\frac{7}{0}$ Substernal pain is not necessarily of cardiac origin; œsophageal pain may be indistinguishable from $N$ that of myocardial infarction. The second type of $N$ pain is pleural pain, which is usually only present if subpleural infarction occurs. Cyanosis is com- $\sigma$ mon and is due partly to the low cardiac output (stagnant anoxia) and partly to the development of right to left shunts in the lungs (Robin and others, 1960; Stein, Forkner, Robin and Wessler, 1961). Circulatory collapse may occur when the pulmonary circulation is severely obstructed. The cause of the shock is probably a combination of $\frac{}{\mathbb{D}}$ 
low cardiac output and reflex peripheral vasodilatation. Transient loss of consciousness is not uncommon. Overloading of the right heart manifests itself by increased jugular venous pressure and electrocardiographic changes (Krause and Silverblatt, 1955). The increased venous pressure is often an indication of the increased filling pressure required to maintain the cardiac output against an increased resistance rather than a sign of heart failure. Electrocardiographic changes are by no means always present even in clinically apparent embolism. Similarly, although radiographic changes of dilatation of the pulmonary artery and increased translucency of the affected lung have been described, X-ray changes are uncommon in embolism uncomplicated by infarction. When infarction occurs linear or wedge-shaped opacities may be seen on the X-ray. Hæmoptysis is not a characteristic sign of uncomplicated embolism and only occurs if infarction is present; even so, only about $50 \%$ of cases of infarction suffer from hæmoptysis.

\section{The Fate of Pulmonary Emboli}

Patients who are known to have had a pulmonary embolism often show no clinical abnormality afterwards and cardiac and respiratory tests may be normal when carried out a few months or years afterwards (Dunér, Pernow and Rignér, 1960). Many of these emboli, to judge from the symptoms and signs at the time of impaction, must have been fairly massive. On the other hand, some patients, particularly those with repeated emboli, may develop cor pulmonale afterwards (Ehrner, Garlind and Linderholm, 1959). Most emboli are composed of blood thrombus, which is susceptible to attack by fibrinolytic mechanisms. The recovery of function after ro-day-old autologous thrombi had been impacted in the pulmonary arteries of dogs has been followed by serial bronchospirometry and measurement of diffusing capacity (Marshall and others, in preparation). The recovery of oxygen uptake by the embolized lung started a few minutes after the embolus had impacted, was rapid over the first few days and then slowed down so that when the dogs were sacrificed at 14 days the lung had recovered about $80 \%$ of its original function.

\section{Pathology}

Blood clot emboli in dogs become adherent to the vessel wall and overgrown by 'endothelium' (Allison, Dunnill and Marshall, 1960). Vascularization of the vessel wall increases at the point of attachment of the clot and capillaries and fibroblasts grow into the clot. The clot is rapidly absorbed so that in dogs examined at 21 days there was no recognizable clot, but only focal areas of subintimal fibrosis containing blood vessels. In these dogs there was no evidence of secondary thrombosis around the original embolus, but secondary thrombosis, proximal and distal to the embolus, has been reported to be common in man (Schoenmackers, 1958) and to be responsible for extensive infarction in some cases.

Todd (I959) has demonstrated by histochemical methods that fibrinolysin activators are present in the intima of the pulmonary artery and also in veins, but are absent from systemic arteries. This is of interest in view of the tendency of pulmonary thrombosis to occur in patients with pulmonary hypertension. The thrombosis may occur, not because of intimal damage to the arteries, but because the pulmonary arteries resemble systemic vessels and do not contain fibrinolysin activator.

\section{Incidence}

Pulmonary embolism has been reported to occur in 5 to $14 \%$ of all autopsies (Parker and Smith, 1958) and at the Radcliffe Infirmary at Oxford during the year 1957 pulmonary embolism was the cause of death in $70(8 \%)$ of the 838 autopsies. Such post-mortem evidence of infarction is probably an underestimate of the total cases because small emboli may be missed and old emboli may be absorbed or may only be evident as changes in the vessel wall (Harrison, 1948; Allison and others, 1960).

Pulmonary infarction commonly accompanies embolism in old patients and in patients with congestive heart failure or pulmonary infections (Roach and Laufman, 1954), but it is unusual in young patients with no complicating factors. It is usually stated that pulmonary infarction does not occur in normal lung in which only the pulmonary artery is obstructed; the bronchial artery supply is sufficient to maintain the nutrition of the lung. The lung can withstand ischæmia extremely well. During replantation of dog lungs the lung may be completely ischæmic and unventilated for over two hours without apparent damage. Ligature of the pulmonary veins in dogs causes hæmorrhagic œdema of the affected lung. Venous thrombosis may be essential for infarction to develop. In a lung affected by œdema or with increased secretions bronchial obstruction may easily occur, cutting off the direct supply of oxygen to the lung parenchyma and facilitating tissue necrosis.

\section{Prevention}

Most cases of pulmonary embolism occur in patients with congestive heart failure or after operations and methods of prevention should be directed towards preventing peripheral venous thrombosis in these patients. Although pulmonary embolism typically occurs about Io days after 
operation, the pathological process leading to this event probably starts on the operating table. Considerable venous stasis has been demonstrated in the legs of patients lying horizontally on an operating table (McLachlin, McLachlin, Jory and Rawling, I960); radio opaque dye injected into the veins may remain for up to one hour in the valve sinuses of the deep veins of the legs. This stasis, often accompanied by prolonged pressure on soft tissues and by accentuation of the clotting factors as a result of the operative trauma, may well initiate thrombus formation which extends during the quiet post-operative period. Measures to prevent thrombosis should be taken throughout the period that the patient is anæsthetized; early active movements after operation may be too late. Raising the legs to $15^{\circ}$ above horizontal has been shown to reduce venous stasis during operation and this should be combined with the avoidance of pressure on the leg muscles.

The prevention of thrombosis in patients with congestive heart failure is more difficult. The oldfashioned 'donkey' which lay under the knees of an orthopnœic patient and which prevented venous return from the legs has passed out of use. In patients who are confined to bed active or passive movements of the legs combined with periodical elevation will help to prevent stasis in the legs, but can do little to prevent thrombosis in the pelvic veins. Anticoagulants are of some value in avoiding thrombosis, but are by no means a sure preventative. Once thronibosis has occurred treatment is directed towards keeping the thrombi in the peripheral veins until they have become organized or absorbed, or towards preventing their passage to the heart and lungs. Immobilization of the legs is widely practised, but if this is to be effective it should probably be maintained rigorously for several weeks. Ligature of the inferior vena cava is now seldom used because of the leg œdema which it often causes, but ligature of the common iliac veins allows collateral venous circulation to develop and is used in selected cases. Suitable patients for vein ligation are those with recurrent emboli and obvious thrombosis in the legs.

\section{Embolism by other Substances than Blood Clots or Thrombi}

Substances other than blood clot which may cause pulmonary embolism are fat, amniotic fluid, air and tumour cells. Damage to the placenta may allow the passage into the maternal circulation of amniotic fluid containing desquamated cells, meconium, hairs and other debris. This results in severe shock which may be partly an anaphylactic reaction to the amniotic fluid in addition to the effect of blockage of the pulmonary capillaries.
Fat embolism may occur following fracture of bones or damage to fatty tissues. This may cause symptoms similar to those of blood-clot embolism? but, in addition, some of the fat may be squeezed: through the pulmonary capillaries and caus cerebral embolism. Air in the pulmonary circulao tion causes obstruction because the surface tensio of the air-blood interface is too great to allow the air to be forced through the pulmonary capillarie 8 by the right heart. Emboli of tumour cells may be fairly large, as when a fragment breaks off a hypere nephroma growing into the inferior vena cava, oP there may be multiple small emboli from a chorion $\overrightarrow{-}$ epithelioma. Embolism by chorionepitheliom cells usually occurs insidiously and is one of the common causes of 'primary' pulmonary hyper 3 . tension. Tumour cell emboli are not susceptible to attack by fibrinolysins and are probably more effective in causing permanent blockage of the pulmonary vessels than are small blood-clot emboli.

\section{Treatment}

The effects of pulmonary embolism, for whicly treatment may be required, can be considered under three headings:

\section{(I) Obstruction to the Circulation}

The right ventricle may fail as a result of the increased resistance against which it has to w and the reduced cardiac output may be unable te maintain the systemic blood pressure, causing stagnant anoxia and clinical 'shock'. Morphine is usually of considerable value in countering the patient's anxiety-in spite of its action in lowering peripheral vascular resistance. If the systemic pressure is very low 1-noradrenaline may be required to increase the peripheral resistance. This drug has only a weak action on the pulmonar circulation, so that its use in pulmonary embolism. is not contraindicated. Digitalis is reported to be of little value unless the heart was in failure before. the onset of embolization. Oxygen administration increases the oxygen-carrying power of the blood by virtue of the dissolved oxygen and is also valuable because the diffusing capacity of tho lungs may be reduced in patients with heart diseas. or pulmonary œdema. An apparatus should be used which gives as high as possible a concentration of oxygen. Venesection is contraindicateds because it results in further lowering of the cardia output.

\section{(2) Possible Reflex Effects}

The existence of reflex vasoconstriction as result of pulmonary embolism has not been sub stantiated and neither in experimental animals noB in human cases have "vasodilators' been found to be of benefit. Atropine and papaverine have beerion 
the drugs most commonly tried for this purpose. Reflex bronchoconstriction may occur as a result of embolism. Broncho-constriction of the embolized lung is beneficial in reducing the ventilation of the non-perfused lung (Severinghaus and others, 1961 ), but if it is generalized it may require treatment and aminophylline is probably the most effective drug.
(3) Superadded Thrombosis

Thrombosis may occur in the branches of the pulmonary artery affected by the embolus (Schoenmackers, 1958) and lead to infarction. The thrombotic process in the peripheral veins also requires treatment and favours the administration of anticoagulants in all cases. Hæmorrhagic infarction is not a contraindication.

\section{REFERENCES}

Allison, P. R., Dunnill, M. S., and Marshall, R. (1960): Pulmonary Embolism, Thorax, I5, 273.

Brofman, B. L., Charms, B. L., Kohn, P. M., Elder, J., Newman, R., and Rizika, M. (i957): Unilateral Pulmonary Artery Occlusion in Man, $\mathcal{F}$. thorac. Surg., 34, 206.

Comroe, J. H., Van Lingen, B., Stroud, R. C., and Roncoroni, A. (I953): Reflex and Direct Cardiopulmonary Effects of 5-OH-Tryptamine (Serotonin): Their Possible Role in Pulmonary Embolism and Coronary Thombosis, Amer. F. Physiol., r73, 379.

Dalpy, R. (1957): The Autonomic Nervous System and its Relationship to Some Forms of Heart and Lung Disease, Brit. med. $\mathscr{Y}$., ii, 24.9.

Dunter, H., Pernow, B., and Rigner, K. G. (1960): The Prognosis of Pulmonary Embolism: A Medical and Physiological Follow-up Examination of Patients Treated at the Department of Internal Medicine and Surgery, Karolinska Sjukhuset, in 1952-58, Acta med. scand., 168, 381 .

Ehrner, L., Garlind, T., and Linderholm, H. (r959): Chronic Cor Pulmonale Following Thromboembolism: A Clinical and Pathophysiological Study of Three Cases, Ibid., 164, 279.

Harrison, C. V. (1948): Experimental Pulmonary Arteriosclerosis, F. Path. Bact., 60, 289.

Julian, D. G., Travis, D. M., Robin, E. D., and Crump, C. H. (I960): Effect of Pulmonary Artery Occlusion Upon End-tidal $\mathrm{CO}_{2}$ Tension, $\mathcal{F}$. appl. Physiol., 15, 87 .

Krause, S., and SilverblatT, M. (1955): Pulmonary Embolism: A Review with Special Emphasis on Clinical and Electro-cardiographic Diagnosis, Arch. intern. Med., 96, 19.

McEvoy, R. K., HARDER, R. A., and DAle, W. A. (1958): Respiratory and Cardiovascular Phenomena Associated with Pulmonary Embolism, Surg. Gynec. Obstet., I06, 271.

Mclachlin, A. D., Mclachlin, A. J., Jory, T. A., and Rawling, E. G. (1960): Venous Stasis in the Lower Extremities, Ann. Sirg., I52, 678.

Marshall, R., Allison, P. R., Bosman, A. R., Sabiston, D. C., and Dunnill, M. S.: A Study of the Immediate and Later Effects of Pulmonary Embolism by Large Blood Thrombi in Dogs (in preparation).

INmen, A. H., and Aviado, D. M. (1956): Effects of Pulmonary Embolism on the Pulmonary Circulation with Special Reference to Arteriovenous Shunts in the Lung, Circulat. Res., 4, 67.

Parker, B. M., and Smith, J. R. (1958): Pulmonary Embolism and Infarction, Amer. F. Med., $24,402$.

Ronch, H. D., and Laufman, H. (1955): Relationship Between Pulmonary Embolism and Pulmonary Infarction: and Experimental Study, Ann. Surg., I42, 82.

Robin, E. D., Forkner, C. E., Bromberg, P. A., Croteau, J. R., and Travis, D. M. (i 96o): Alveolar Gas Exchange in Clinical Pulmonary Embolism, New Engl. F. Med., 262, 283.

Sanders, R., WaAlkes, J. P., Gilbert, J. W., and TerRy, L. L. (1959): Serotonin (5-Hydroxytryptamine) and Pulmonary Thromboembolism, Surg. Gynec. Obstet., ro9, 455.

Schoznmackers, J. (1958): Zur Pathologie der Lungenarterienembolie, Dtsch. med. Wschr., 83, i 15.

Severinghaus, J. W., and Stupfel, M. (r957): Alveolar Dead Space as an Index of Distribution of Blood Flow in Pulmonary Capillaries, F. appl. Physiol., ro, 335 .

-, Swenson, E. W., Finley, T. N., Lategola, M. T., and Williams, J. (I96r): Unilateral Hypoventilation Produced in Dogs by Occlusing One Pulmonary Artery, Ibid., 16, 53.

Stein, M., Forkner, C. E., Robin, E. D., and Wessler, S. (I96I): Gas Exchange After Autologous Pulmonary Embolism in Dogs, Ihid., I6, 488 .

Topn, A. S. (r959): The Histological Localization of Fibrinolysin Activator, F. Path. Bact., 78, 28r.

Williams, M. H. (1956): Mechanical versus Reflex Effects of Diffuse Pulmonary Embolism in Anæsthetized Dogs, Circulat. Res., 4, 325. 